\title{
UMA ARQUITETURA PEDAGÓGICA PARA EDUCAÇÃO À DISTÂNCIA SOBRE PREVENÇÃO E MANEJO EM ACIDENTES DO TRABALHO COM MATERIAL BIOLÓGICO
}

Fabiana Feijó Costa - PPGENSAU/UFCSPA - fabi.costa@icloud.com - 0000-00033246-2720

Sílvio César Cazella - PPGENSAU/UFCSPA - silvioc@ufcspa.edu.br - 0000-00032343-893X

Márcia Rosa da Costa - PPGENSAU/UFCSPA - marciarc@ufcspa.edu.br - 0000-00033340-0644

Resumo: Este artigo apresenta o desenvolvimento de uma Arquitetura Pedagógica (AP) para Educação Permanente em Saúde (EPS), na modalidade de Educação à Distância $(\mathrm{EaD})$, utilizando a metodologia ativa denominada estudo de caso, abordando a prevenção e o atendimento de acidentes do trabalho com material biológico. A geração de dados ocorreu por meio de amostragem não probabilística, na qual a AP elaborada foi submetida a avaliação de especialistas. Em suas avaliações os profissionais demonstraram concordância, referindo que a AP está alinhada aos seus propósitos e metas, coerente quanto à organização, estrutura, estratégia, coerência e suficiência, bem como significância, impacto, motivação e interesse. Com base no exposto, a AP pode contribuir como importante ação de educação permanente em saúde.

Palavras-chave: Arquitetura Pedagógica; Educação Permanente em Saúde; Competências; Acidente do trabalho com material biológico; Prevenção.

\section{A PEDAGOGICAL ARCHITECTURE FOR DISTANCE EDUCATION ON PREVENTION AND MANAGEMENT IN ACCIDENTS AT WORK WITH BIOLOGICAL MATERIAL}

\begin{abstract}
This article presents the development of a Pedagogical Architecture (AP) for Permanent Health Education (EPS), in the Distance Education (DE) modality, using the active methodology called case study, addressing accident prevention and care of working with biological material. Data generation took place through non-probabilistic sampling, in which the elaborated PA was submitted to expert evaluation. In their assessments, the professionals demonstrated agreement, referring that the PA is aligned with its purposes and goals, consistent in terms of organization, structure, strategy, coherence and sufficiency, as well as significance, impact, motivation and interest. Based on the above, the PA can contribute as an important action for permanent health education.
\end{abstract}

Keywords: Pedagogical Architecture; Permanent Health Education; Skills; Work accident with biological material; Prevention.

\section{INTRODUÇÃO}

As relações intrínsecas entre o trabalho e as condições de vida do ser humano podem determinar sua saúde ou a falta dela, dependendo da forma de condução e equilíbrio entre estas duas esferas (MARZIALE, 2010). O cenário atual da temática saúde do trabalhador, os acidentes e óbitos relacionados às atividades laborais apresentam-se como questões de extrema relevância e impacto na morbimortalidade do país. Dados recentes, referentes à incidência de acidentes do trabalho ocorridos em 2017, demonstram 
549.405 casos, que foram notificados e apresentados pela Secretaria de Previdência do Ministério da Fazenda em seu documento denominado Anuário Estatístico de Acidentes do Trabalho (BRASIL, 2017).

Diante deste cenário, entende-se que as ações de Educação Permanente em Saúde (EPS) podem contribuir de forma significativa para instrumentalizar os profissionais da saúde, possibilitando a ampliação do conhecimento e a adoção de uma postura proativa para a prevenção de eventos indesejáveis relacionados ao trabalho, bem como para a condução dos protocolos de atendimento condizentes com as necessidades. A educação no trabalho, incorporada ao cotidiano da área da saúde, pode ser melhor explorada e tornar-se mais proveitosa com o uso das metodologias ativas, processos interativos de conhecimento, que despertam a curiosidade e o envolvimento ativo do discente em seu processo de formação. Para Lysakowski, Caregnato e Sudbrack (2016), o ensino na saúde mostra-se como possibilidade na construção de embasamento para a prática da saúde preventiva e promoção da qualidade de vida da população. Nesse sentido, os Ambientes Virtuais de Aprendizagem (AVA) surgem como alternativa para a prática da EPS, sobretudo para inserção da modalidade de Ensino à Distância $(\mathrm{EaD})$, direcionada a profissionais da saúde (BONES; COSTA; CAZELLA, 2016). As Tecnologias de Informação e Comunicação (TICs), como recursos de armazenamento, processamento e comunicação de informação, ampliam as possibilidades de acesso à educação, uma vez que não há mais tempo ou local fixo para este processo. Especialmente para os profissionais da saúde, o EaD tem sido uma alternativa viável como estratégia para EPS, em função de facilitar o acesso à informação, considerando-se também as dimensões geográficas que podem dificultar o deslocamento daqueles que estão distantes dos centros urbanos, comumente núcleos de formação (OLIVEIRA, 2007).

Para orientar estas ações propõe-se a elaboração de uma Arquitetura Pedagógica (AP), ou seja, um sistema de premissas teóricas que explica e orienta a forma como se aborda o currículo, que se concretiza nas práticas pedagógicas e nas interações entre professor e aluno (BEHAR, 2009). Neste estudo, a AP está relacionada às ações de prevenção e manejo de acidentes do trabalho com material biológico e destina-se ao desenvolvimento de algumas competências, necessárias ao adequado manejo diante da ocorrência de tais agravos.

Este artigo está organizado em seis módulos, dos quais o primeiro módulo apresenta a introdução, o segundo módulo aborda o mapeamento das competências necessárias e aquelas a serem desenvolvidas. O terceiro módulo traz o conceito e a organização de uma AP, o quarto módulo identifica a metodologia, o quinto módulo apresenta os dados gerados e a discussão. O sexto módulo finaliza o estudo, apresentando as considerações finais.

\section{MAPEAMENTO DE COMPETÊNCIAS}

Os currículos baseados em competências propõem centrar a perspectiva no aluno e na aprendizagem, não no professor e ensino (BEHAR; MASSARO, 2012; BEHAR; SCHNEIDER, 2016). Competência pode ser definida como a capacidade de mobilizar conhecimentos para o enfrentamento de uma determinada situação, e considera três elementos: Conhecimentos, Habilidades e Atitudes, sintetizados na sigla CHA. Considerando-se os pilares da educação como aprender a conhecer, aprender a fazer, aprender a conviver e aprender a ser, é importante ressaltar a sua associação com os elementos do CHA (BEHAR; MASSARO, 2012; BEHAR; SCHNEIDER, 2013). Conhecimento é construído através das relações com o meio, não é sinônimo de obter informação, mas sim poder utilizá-la em momentos distintos. O conhecimento resulta das V. $19 \mathrm{~N}^{\mathrm{o}} 1$, julho, 2021 RENOTE 
estruturas cognitivas do sujeito e de interações entre o sujeito e o objeto. Habilidade é uma ação automatizada, operacional, um procedimento já construído. Indica capacidade adquirida, o saber fazer. Atitude revela o modelo mental do sujeito, suas crenças e valores. Está relacionada com as intenções e vontades, é uma escolha em relação aos acontecimentos. É a prontidão para agir, o elemento pelo qual a competência se concretiza.

A seguir são apresentadas as competências necessárias aos enfermeiros e técnicos de enfermagem referente às medidas de proteção à segurança dos trabalhadores dos serviços de saúde, com base na Norma Regulamentadora 32 (NR32) e demais normativas legais.

1. Medidas de controle que minimizem a exposição aos agentes biológicos: Os enfermeiros e técnicos de enfermagem têm o conhecimento sobre as medidas necessárias para a redução de exposição aos agentes biológicos durante as atividades de trabalho.

2. Normas e procedimentos de higiene: Os profissionais conhecem os procedimentos de higiene que devem ser adotados quando atuam em estabelecimentos de saúde.

3. Utilização de equipamentos de proteção coletiva, individual e vestimentas de trabalho: Os profissionais da enfermagem conhecem os equipamentos de proteção necessários para a execução de suas atividades de trabalho e as vestimentas apropriadas, conforme a atividade realizada.

4. Medidas para a prevenção de acidentes e incidentes: Os profissionais reconhecem as principais condutas de segurança no ambiente de trabalho para a preservação de sua integridade física.

5. Medidas para a prevenção de contaminação para os profissionais expostos ao risco biológico: Os profissionais conhecem o Programa Nacional de Imunizações (PNI) e as demais vacinas indicadas, em função de suas atividades laborais.

6. Medidas a serem adotadas pelos trabalhadores no caso de ocorrência de incidentes e acidentes de trabalho com material biológico: Os profissionais conhecem as condutas a serem adotadas diante da ocorrência de um acidente em seu local de trabalho.

Para o contexto do EaD são necessários alguns domínios e suas competências, como segue. Domínio tecnológico: competências relacionadas ao uso dos recursos tecnológicos no EaD, como, por exemplo, os ambientes virtuais de aprendizagem, objetos de aprendizagem, ferramentas em geral. Objetos de Aprendizagem (OA) são recursos, digitais ou não, que podem ser utilizados, reutilizados ou referenciados durante a aprendizagem apoiada na tecnologia. Como exemplo tem-se as imagens, os vídeos e os portais. Domínio sociocultural: competências que se referem aos aspectos sociais e culturais nos quais o sujeito está inserido, com foco no trabalho em equipe. As atitudes são o fator chave para a competência do trabalho em equipe. Domínio cognitivo: competências pautadas no sujeito e sua aprendizagem, na construção do conhecimento, coordenação das ações e organização pessoal. Domínio de gestão: competências envolvidas nas atividades em nível administrativo e acadêmico na $\mathrm{EaD}$, incluindo organização do tempo (professor, aluno e tutor) e planejamento das práticas pedagógicas. A utilização de todos ou algum domínio dependerá do contexto em que o aluno está inserido.

\section{ARQUITETURA PEDAGÓGICA}

A AP pode ser considerada como uma estrutura de trabalho, elaborada a partir da 
vivência do docente, adaptável a diferentes enfoques temáticos e diferentes ambientes socioeducativos, que se apoiam na articulação entre a epistemologia genética de Piaget e a pedagogia da pergunta de Paulo Freire (ARAGÓN, 2016).

As APs propõem, às tecnologias, sentidos que ultrapassam o seu uso periférico e dissociado das práticas pedagógicas, no intuito de explorar novas possibilidades de referenciamento dos espaços e tempos, ressignificando os papéis e as formas de mediação, oferecendo assim condições estruturantes para as construções coletivas (ARAGÓN, 2016).

Para Behar (2009), as AP são:

[...] um sistema de premissas teóricas que representa, explica e orienta a forma como se aborda o currículo e que se concretiza nas práticas pedagógicas e nas interações professor-aluno-objeto de estudo/conhecimento. (BEHAR, 2009, p. 24).

Elas vão além da orientação e explicação dos elementos curriculares, são compostas por quatro aspectos: Aspectos organizacionais; Aspecto de conteúdo; Aspectos metodológicos; Aspectos tecnológicos.

Como elemento facilitador do processo de aprendizagem tem-se os Objetos de Aprendizagem (OA). Para Behar (2009), um OA pode ser "qualquer material digital, como, por exemplo, textos, animações, vídeos, imagens, aplicações, páginas na web, de forma isolada ou em combinação, com fins educacionais". Assim, podem ser considerados $\mathrm{OA}$ aqueles recursos que possuem fins educativos e embasamento pedagógico, podendo ser utilizados para aprendizagem presencial ou EaD.

\section{METODOLOGIA}

Este estudo foi construído como exploratório e a geração de dados ocorreu por meio de amostragem não probabilística, por julgamento, ou seja, aquela em que para a seleção da amostra o pesquisador usa o seu julgamento para selecionar os membros da população que são boas fontes de informação precisa (OLIVEIRA, 2001). Esta escolha justifica-se pelo estilo do estudo proposto, no qual foi apresentada a AP aos especialistas e solicitado que emitissem seus pareceres, no sentido de validar ou não a proposta.

Para que se pudesse realizar a avaliação e validação da AP proposta, buscou-se uma ferramenta apropriada, com embasamento científico para esta finalidade, denominada Instrumento de Validação de Conteúdo Educativo em Saúde (IVCES). O IVCES tem como objetivo a validação de conteúdo escrito dos materiais educativos em saúde, constituindo-se em material orientador para a construção destes (LEITE et al., 2018, p. 1734). O instrumento utilizado, adaptado do IVCES, foi composto por dez questões, com opções de respostas 0 discordo totalmente; 1 discordo; 2 indiferente; 3 concordo; 4 concordo totalmente.

\section{RESULTADO E DISCUSSÃO DOS DADOS}

Uma AP, considerando a proposta de Sonego et al. (2018), contempla em seus aspectos componentes, os organizacionais, de conteúdo, metodológicos e tecnológicos. Os aspectos organizacionais compreendem a carga horária, modalidade, público-alvo e atores envolvidos. Os aspectos de conteúdo compreendem o detalhamento dos assuntos a serem trabalhados, como a prevenção, definições sobre acidentes do trabalho e condutas adequadas. Já os aspectos metodológicos delineiam as estratégias a serem adotadas para a condução da educação permanente e os aspectos tecnológicos detalham o Ambiente Virtual de Aprendizagem (AVA) e recursos propostos, bem como o endereço para acesso. 
A figura 1 apresenta a AP desenvolvida.

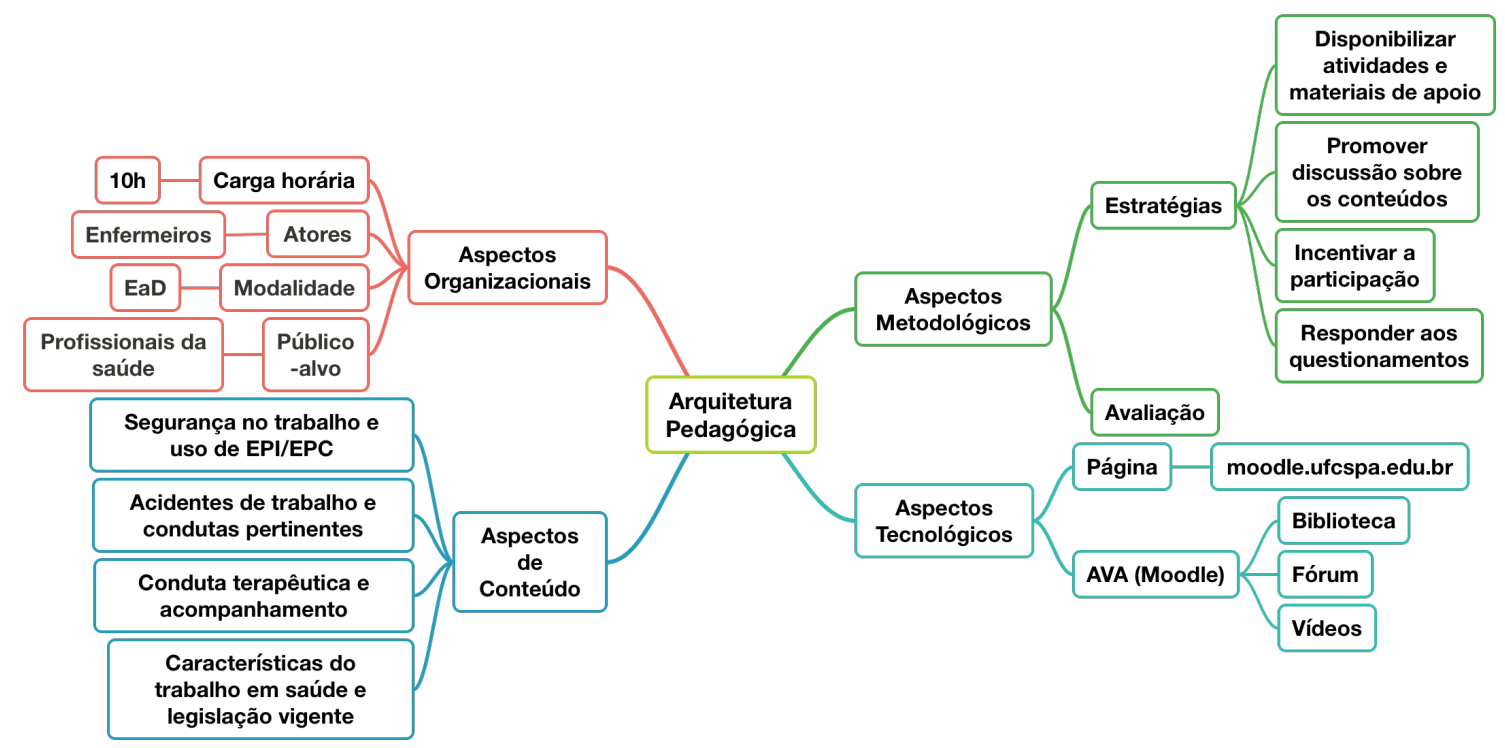

Figura 1 - AP desenvolvida

Fonte: A autora (2020), Adaptado de Sonego et al. (2018).

\subsection{ASPECTO ORGANIZACIONAL}

Envolve o planejamento, organização do tempo e espaço, expectativas e propostas pedagógicas, objetivos, atores, público-alvo e modalidade de ensino.

Esta AP fundamenta um curso, na modalidade $\mathrm{EaD}$, com carga horária total de 10 horas, divididas em 4 módulos e duração aproximada de cinco dias para sua conclusão, apresentados na figura 2 .

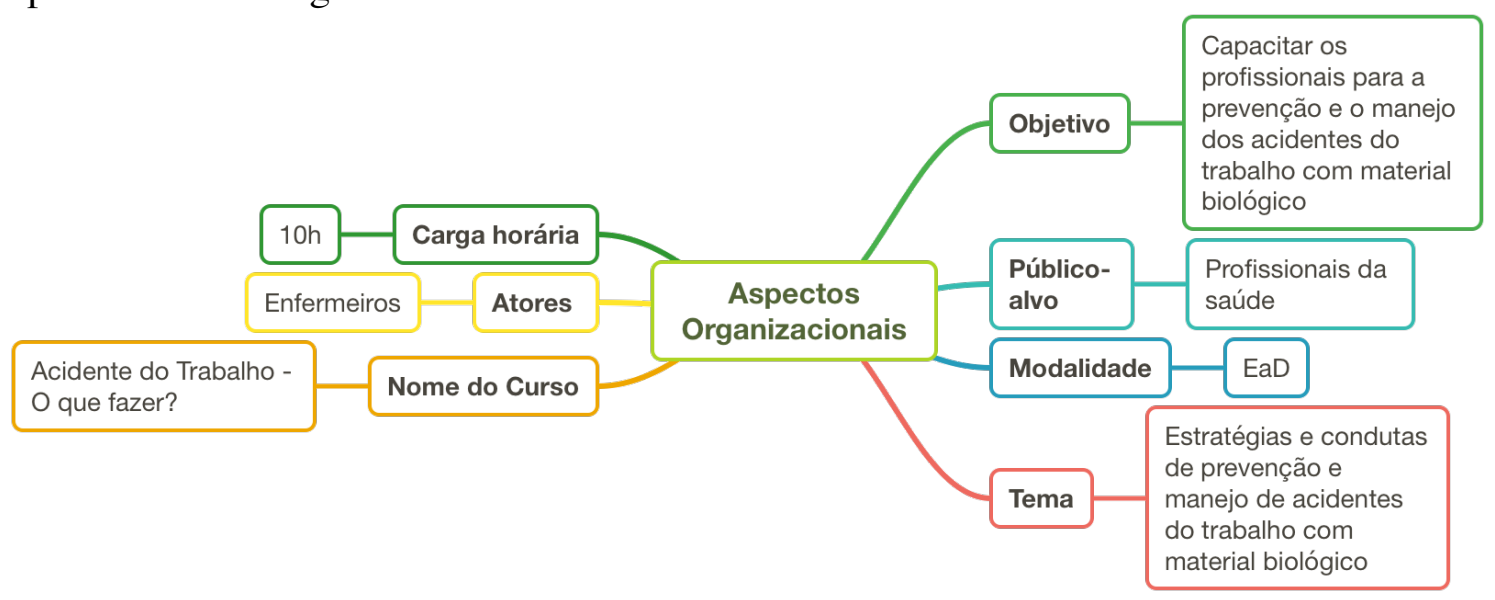

Figura 2 - Aspectos Organizacionais da AP desenvolvida

Fonte: Elaborado pela Autora (2020).

\subsection{ASPECTO DE CONTEÚDO}

O conteúdo está relacionado ao assunto que será abordado na AP, que poderá ser trabalhado de forma conceitual, factual, atitudinal e procedimental. O planejamento cuidadoso destes elementos gera condições para a construção de conhecimento, desenvolvimento de capacidades, habilidades e competências (BEHAR, 2009). O aspecto 
de conteúdo é o momento no qual são descritos os materiais didáticos (vídeos, áudios, imagens, objetos de aprendizagem, entre outros), recursos e atividades de estudo, o qual está detalhado na figura 3 .

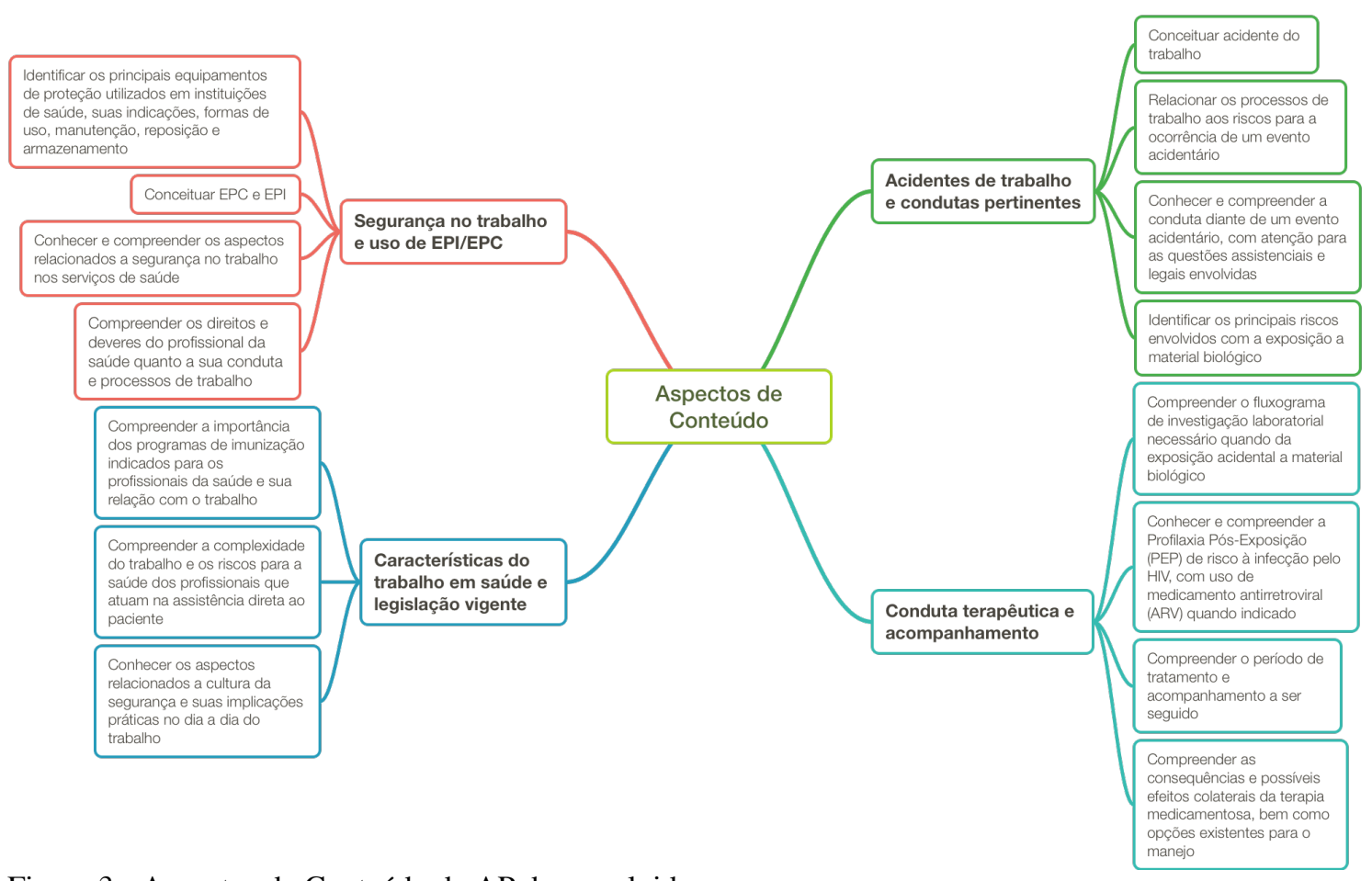

Figura 3 - Aspectos de Conteúdo da AP desenvolvida Fonte: Elaborado pela Autora (2020).

\subsection{ASPECTO METODOLÓGICO}

Envolve as formas de comunicação, interação e procedimentos de avaliação. Diz respeito à seleção das técnicas e procedimentos a serem utilizados, bem como sua relação e estruturação. $\mathrm{O}$ aspecto metodológico tem relação direta com os objetivos do curso, representa a forma de atingir os objetivos propostos e engloba os processos de avaliação (BEHAR, 2009) e está apresentado na figura 4.

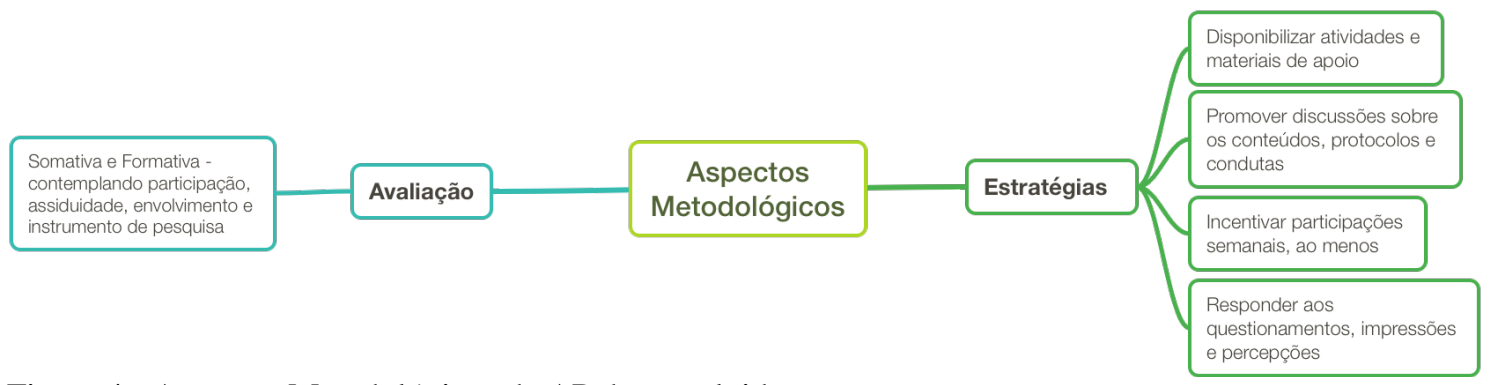

Figura 4 - Aspectos Metodológicos da AP desenvolvida Fonte: Elaborado pela Autora (2020).

Como estratégia metodológica foi escolhido o estudo de caso, em função de suas características, especialmente porque este método engloba análise objetiva de situações e elaboração de propostas para a solução da situação problema. Esta abordagem está em alinhamento com o tema do estudo, uma vez que o curso embasado pela AP busca instrumentalizar os profissionais para a prevenção e o manejo diante de um acidente do 
trabalho com material biológico. Diante dos conhecimentos desenvolvidos durante o curso, os discentes serão conduzidos a análise de uma situação real (relato de um acidente que tenha ocorrido com profissional assistencial), com levantamento de hipóteses e busca de alternativas para a solução.

A estratégia Estudo de Caso tem o objetivo de conduzir o aluno para a análise de problemas e tomada de decisões, diante de um caso que pode ser real ou fictício, no qual os alunos analisam e elaboram conclusões, com base em conceitos já estudados. É utilizada para colocar o discente diante de situações possíveis, para que ele possa tomar decisões após a análise dos diferentes ângulos de cada situação. Oportuniza a elaboração de um potencial de argumentação, envolve tanto a construção do conhecimento quanto síntese (ANASTASIOU; ALVES, 2004).

\subsection{ASPECTO TECNOLÓGICO}

Compreende a escolha de um ambiente virtual de aprendizagem e de outras tecnologias (figura 5). Dentre os vários AVAs existentes, esta AP utiliza o Modular Object-Oriented Dynamic Learning Environment (Moodle),por ser um software livre, utilizado pela Universidade Federal de Ciências da Saúde de Porto Alegre (UFCSPA) e também pela grande maioria das instituições hospitalares, onde este estudo será proposto. Este AVA está disponível em: https://moodle.ufcspa.edu.br

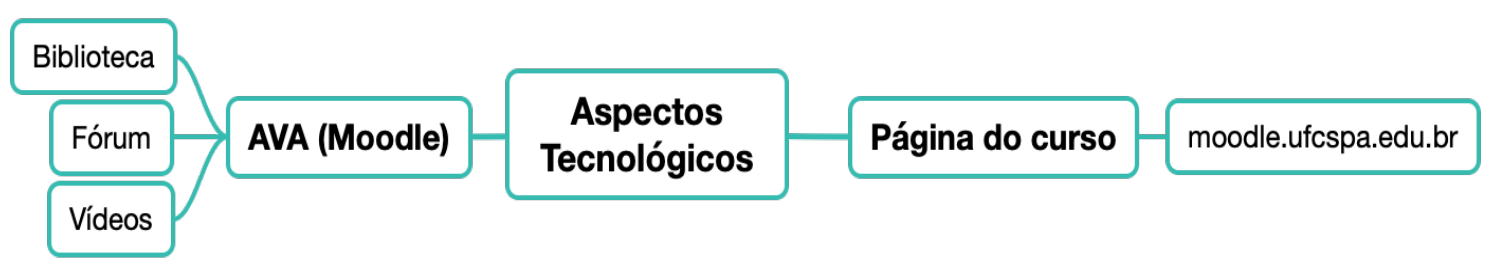

Figura 5 - Aspectos Tecnológicos da AP desenvolvida Fonte: Elaborado pela Autora (2020).

Como avaliadores do estudo foram eleitos vinte profissionais, com formação em enfermagem e especialização em enfermagem do trabalho, atuantes em instituições hospitalares e instituições de referência para a saúde do trabalhador na cidade de Porto Alegre. Inicialmente também haviam sido eleitos como sujeitos do estudo professores pedagogos atuantes na UFCSPA, mas em função de intercorrências geradas pela pandemia e dificuldade para comunicação, optou-se pela inserção somente dos profissionais enfermeiros. A escolha dos participantes ocorreu em função de sua experiência e conhecimento da área, características fundamentais para que pudessem atuar como avaliadores, compondo uma amostragem não probabilística. Para estes atores foi encaminhado o questionário, via Google forms, para que pudessem emitir suas opiniões sobre a AP proposta. As questões que compuseram o questionário foram categorizadas em módulos, sendo que o primeiro módulo avaliou os objetivos do estudo, ou seja, seus propósitos, metas ou finalidades. Já o segundo módulo avaliou a estrutura e apresentação, contempla a organização, estrutura, estratégia, coerência e suficiência da AP. O módulo final avaliou a relevância, abordou a significância, impacto, motivação e interesse despertado pela AP proposta. Do grupo, oito profissionais responderam as questões, caracterizando-se como sujeitos da pesquisa.

As participantes foram todas mulheres, se encontram em faixas etárias distintas, estando uma entre 20 e 30 anos, três entre 31 e 40 anos e quatro com mais de 40 anos. Quanto ao tempo de experiência profissional, identificou-se uma enfermeira com mais de V. $19 \mathrm{~N}^{\mathrm{o}} 1$, julho, 2021 RENOTE 
20 anos de experiência profissional e sete com mais de cinco anos de atuação.

A estatística descritiva foi escolhida para a análise dos dados devido ao pequeno tamanho amostral. As variaveis quantitativas foram descritas por média e as categóricas por frequências absolutas e relativas.

Quando observamos as respostas relacionadas ao primeiro módulo de perguntas, relacionado aos objetivos (propósitos, metas ou finalidades) temos a totalidade das respostas concordando totalmente com o fato de que a AP contempla o tema proposto, ou seja, $100 \%$ das enfermeiras consideram que o tema está contemplado. A adequação ao processo de ensino-aprendizagem foi pontuada por $1(12,5 \%)$ como concordo e por 7 $(87,5 \%)$ enfermeiras como concordo totalmente, sugerindo um acordo de todas as enfermeiras quando a adequação da AP ao processo de ensino-aprendizagem. No item que questiona se a AP esclarece dúvidas sobre o tema abordado, houve $2(25 \%)$ respostas concordando e $6(75 \%)$ concordando totalmente com esta afirmativa. Quanto ao questionamento se a AP proporciona reflexão sobre o tema, $2(25 \%)$ das respostas foram concordo e 6 (75\%) concordo totalmente, o que parece estar alinhado com o fato de que, realmente, a AP pode permitir ponderações sobre a temática. Na última pergunta referente ao módulo dos objetivos, que questiona se a AP incentiva mudança de comportamento, as respostas obtidas foram $3(37,5 \%)$ concordo e $5(62,5 \%)$ concordo totalmente, o que permite uma avaliação positiva sobre este item.

Quanto ao segundo módulo, relacionado à estrutura/apresentação (organização, estrutura, estratégia, coerência e suficiência), no qual a primeira questão busca saber se a AP traz as informações necessárias, obteve-se $1(12,5 \%)$ resposta como indiferente, 1 $(12,5 \%)$ como concordo e $6(75 \%)$ como concordo totalmente. Esta resposta como indiferente, traz um alerta para a realização de uma reavaliação da proposta apresentada, pois é oriunda de um grupo de especialistas, configurando-se como um dado significativo, que pode identificar que a AP poderia contemplar mais informações sobre a temática dos acidentes do trabalho.

Ao analisar as respostas que compõem o terceiro módulo, relacionado à relevância (significância, impacto, motivação e interesse), no primeiro questionamento, se a AP estimula o aprendizado, as respostas foram 2 (25\%) concordo e $6(75 \%)$ concordo totalmente. Na segunda questão deste módulo, se a AP contribui para o conhecimento na área as respostas foram $2(25 \%)$ concordo e 6 (75\%) concordo totalmente. Quando o questionamento foi sobre o despertar do interesse pelo tema, as respostas foram $1(12,5 \%)$ indiferente, $2(25 \%)$ concordo e $6(75 \%)$ concordo totalmente.

Segundo a percepção de Gaeta e Masetto (2010), a aprendizagem é um processo complexo e abrangente, que envolve o crescimento e desenvolvimento de um ser humano em sua totalidade. Este estudo e seu produto, a arquitetura pedagógica elaborada, procura estimular os seus discentes a este desenvolvimento. Daí a importância da avaliação dos especialistas, como conhecedores da temática e seus desdobramentos, no sentido de avaliarem e validarem a proximidade do alcance deste objetivo, por meio do preenchimento do instrumento de avaliação. Como forma de corroborar estas proposições, traz-se mais detalhamento da contribuição de Gaeta e Masetto (2010), que apresentam o processo de aprendizagem como abrangendo quatro áreas, quais sejam, a do conhecimento (desenvolvimento intelectual do homem em suas operações mentais como pensar, refletir, analisar, criar), do afetivo- emocional (autoconhecimento, potencialidades e interações sociais), de habilidades (entender a aplicabilidade dos conhecimentos adquiridos e construídos) e de atitudes ou valores (competências para a superação dos desafios, considerando os preceitos de cidadania, respeito e éticos).

Além das reflexões sobre o processo de ensino e aprendizagem, cabe ressaltar a contribuição dos conceitos da EPS, que refere-se à aprendizagem no trabalho, com ênfase 
ao trabalho em equipe, à construção de cotidianos como objetos de aprendizagem individual, coletiva e institucional, conforme Ceccim (2004), podendo ser orientadora das iniciativas de desenvolvimento dos profissionais e das estratégias de transformação das práticas de saúde. Desta forma, a AP aqui apresentada vai ao encontro destas estratégias, na medida em que se propõe a educação dos profissionais em seu ambiente de trabalho, sobre uma temática presente em seu cotidiano, seja após a ocorrência de um evento, ou sob forma de ações preventivas.

\section{CONSIDERAÇÕES FINAIS}

Este estudo está direcionado para a concepção de uma arquitetura pedagógica (AP), que aborda a prevenção e o manejo dos acidentes do trabalho com material biológico, na modalidade de Educação a Distância (EaD), alicerçado nos conceitos da educação permanente em saúde, ou seja, aquela na qual o aprender e o ensinar se incorporam ao cotidiano de trabalho, de forma que os profissionais possam pensar suas práticas de forma proativa e significativa. Como questão central apresenta-se como conceber uma arquitetura pedagógica em educação a distância, com foco nas atitudes preventivas e no manejo proativo diante da ocorrência de um acidente do trabalho.

Diante deste panorama foram mapeadas as competências a serem desenvolvidas, que estão fundamentadas em bases legais, como a NR-32 e orientações protocolares do ministério da saúde. Estas competências nortearam o desenvolvimento da AP, que foi composta por quatro módulos, com uma carga horária total de 10 horas, dividida em 3 horas no primeiro e 3 horas no segundo módulo, 2 horas no terceiro e 2 horas no quarto módulo. Após a elaboração, a AP foi encaminhada aos profissionais especialistas para avaliação. Como o tema abordado é bastante específico, os profissionais eleitos como avaliadores foram selecionados em função de seu conhecimento e experiência, compondo uma amostragem não probabilística. Estes profissionais puderam emitir seus pareceres por meio do instrumento enviado pelo Google forms. Embora o convite tenha sido encaminhado para 20 participantes, obteve-se retorno de 8 participantes, que compuseram a amostra como avaliadores.

Quando retomamos a questão central deste estudo, referente à concepção de uma $\mathrm{AP}$, na modalidade $\mathrm{EaD}$, para a prevenção e manejo de acidentes do trabalho com material biológico, observa-se que o objetivo foi atingido. Esta constatação está relacionada aos dados obtidos nas avaliações realizadas pelos especialistas, nas quais os itens de avaliação, como objetivos, estrutura, apresentação e relevância estavam pontuados positivamente. Reforça esta ideia as observações deixadas pelos avaliadores, quanto a adequação da proposta apresentada e até a expansão da ação educativa para outras categorias profissionais.

Também reforça a afirmação do objetivo do estudo ter sido atingido e sua adequação ao panorama atual, no qual vivenciamos o rápido crescimento das atividades em EaD e o uso das TICs, em função das demandas geradas pela pandemia causada pelo Coronavirus, que levou os indivíduos a uma adaptação ao trabalho e estudo de forma remota, com todas as suas interfaces. Desta forma, as ações de educação permanente em saúde, na modalidade $\mathrm{EaD}$, mostram-se como estratégias eficazes. Estas ações possibilitam o aprimoramento dos conhecimentos, como forma de instrumentalização dos profissionais da saúde para a qualificação de suas práticas, na medida em que seguem suas rotinas de trabalho, com acesso à informação no espaço e tempo que tiverem disponíveis. Tal disponibilidade é aplicada tanto para aqueles que atuam na linha de frente, presencialmente, quanto para aqueles que atuam de forma remota ou em home V. $19 \mathrm{~N}^{\circ} 1$, julho, 2021 RENOTE 
office.

Ainda, como contribuição pode-se destacar a existência de escasso material educativo sobre a temática proposta, especialmente com foco em ações preventivas, que traduzam as normativas legais para o entendimento e compreensão dos profissionais envolvidos com a assistência direta ao paciente.

Como limitação deste estudo pode-se incluir o tamanho da amostra, que foi composta por 8 avaliadores. Entende-se que poderiam haver contribuições para enriquecer o estudo, caso a amostra fosse composta por um número maior de participantes, uma vez que os convidados foram especialistas e conhecedores da temática abordada.

Ressalta-se que este estudo compõe a primeira fase para o desenvolvimento de um curso para EPS, a elaboração da matriz curricular baseada em competências.

Desta forma, trabalhos futuros podem utilizar a AP como base para a produção do curso e sua disponibilização em AVA, com a temática da prevenção e manejo dos acidentes do trabalho com material biológico, avaliando sua aplicação e adesão. Esta seria uma valiosa iniciativa de educação permanente em saúde, disponibilizada aos profissionais.

\section{REFERÊNCIAS}

ANASTASIOU, L.G.C.; ALVES, L.P. Estratégias de ensinagem. In: ANASTASIOU, L.G.C.; ALVES, L.P. (Org.). Processos de ensinagem na universidade: pressupostos para as estratégias de trabalho em aula. 3. ed. Joinville: Univille, 2004. p. 67-100.

ARAGÓN, R. Interação e mediação no contexto das arquiteturas pedagógicas para a aprendizagem em rede. Revista de Educação Pública, Cuiabá, v. 25, n. 59/1, p. 261-75, 2016. ISSN 2238-2097. DOI: https://doi.org/10.29286/rep.v25i59/1.3674.

BEHAR, P.A. Modelos pedagógicos em educação à distância. In: BEHAR, P.A. (Org.). Modelos pedagógicos em educação à distância. 1. ed. Porto Alegre: Artmed, 2009, p. 15-32.

BEHAR, P.A.; MASSARO, G. (Org.). Competências em educação à distância. Penso, v. 5, n. 2, p. 346-50, 2012. DOI: https://doi.org/10.15448/2179-8435.2014.2.17803.

BEHAR, P.A.; SCHNEIDER, D. Modelos pedagógicos e competências em educação à distância: a construção do MP-CompEAD. Revista de Educação Pública, Cuiabá, v. 25, n. 59/2, p. 504-24, 2016. DOI: 10.29286/rep.v25i59/2.3832.

BONES, A.A.N.S.; COSTA, M.R.; CAZELLA, S.C. Educação À distância como estratégia de formação permanente de profissionais de saúde no SUS: análise focada em competências no processo ensino-aprendizagem. In: ALMEIDA, A.N.; CAREGNATO, R.C.A. (Org.). Ensino na Saúde: desafios contemporâneos na integração ensino e serviço. 1. ed. Porto Alegre: Moriá, 2016, p. 87-100.

BRASIL. Ministério da Fazenda. Anuário Estatístico de Acidentes do Trabalho: AEAT. Brasília, DF: Ministério da Fazenda, 2017. 996p.

BRASIL. Ministério da Saúde. Secretaria de Gestão do Trabalho e da Educação na Saúde. V. $19 \mathrm{~N}^{\circ} 1$, julho, 2021 
Departamento de Gestão da Educação em Saúde. Política Nacional de Educação Permanente em Saúde. Brasília: Ministério da Saúde, 2009.

CECCIM, R.B.; FEUERWERKER, L.C.M. O quadrilátero da formação para a área da saúde: ensino, gestão, atenção e controle social. Physis, Rio de Janeiro, v. 14, n. 1, p. 4165, 2004. DOI: http://dx.doi.org/10.1590/S0103-73312004000100004.

GAETA, C.; MASETTO, M. Metodologias ativas e o processo de aprendizagem na perspectiva da inovação. PBL 2010 Congresso Internacional. Anais... São Paulo, 2010. Disponível em: <http://each.uspnet.usp.br/pbl2010/trabs/trabalhos/TC0287-1.pdf>. Acesso em: 01 ago. 2020.

LEITE, S.S.; ÁFIO, A.C.E.; CARVALHO, L.V. et al. Construção e validação de Instrumento de Validação de Conteúdo Educativo em Saúde. Revista Brasileira de Enfermagem, Brasília, v. 71, n. 4, p. 1635-41, 2018. DOI: https://doi.org/10.1590/00347167-2017-0648.

LYSAKOWSKI, S.; CAREGNATO, R.C.A.; SUDBRACK, A. W . O contexto do ensino na saúde no Brasil: da origem à atualidade. In: ALMEIDA, A.N.; CAREGNATO, R.C.A. (Org.). Ensino na Saúde: desafios contemporâneos na integração ensino e serviço. 1. ed. Porto Alegre: Moriá, 2016, p.121-36.

MARZIALE, M.H.P. Contribuições do enfermeiro do trabalho na promoção da saúde do trabalhador. Acta Paulista de Enfermagem, São Paulo, v. 23, n. 2, p. 7, 2010. DOI: https://doi.org/10.1590/S0103-21002010000200001.

OLIVEIRA, M.A.N. Educação à Distância como estratégia para a educação permanente em saúde: possibilidades e desafios. Revista Brasileira de Enfermagem, Brasília, v.60, n.5, p. 585-9, 2007. DOI: https://doi.org/10.1590/S0034-71672007000500019.

OLIVEIRA, T.M.V. Amostragem não probabilística: adequação de situações para uso e limitações de amostras por conveniência, julgamento e quotas. Administração Online, v. 2, n. 3, jul./set. 2001. ISSN 1517-7912.

SONEGO, A.H.S.; RIBEIRO, A.C.R.; MACHADO, L.R.; BEHAR, P.A. et al. Formação de professores: uma arquitetura pedagógica com foco na m-learning. Novas Tecnologias na Educação, Porto Alegre, v. 16, n. 1, p. 301-10, 2018. DOI: https://doi.org/10.22456/1679-1916.89279. 